\title{
Transcriptional and epigenetic regulation of PPARY expression during adipogenesis
}

\author{
Ji-Eun Lee and Kai Ge*
}

\begin{abstract}
The nuclear receptor PPARY is a master regulator of adipogenesis. PPARY is highly expressed in adipose tissues and its expression is markedly induced during adipogenesis. In this review, we describe the current knowledge, as well as future directions, on transcriptional and epigenetic regulation of PPARY expression during adipogenesis. Investigating the molecular mechanisms that control PPARY expression during adipogenesis is critical for understanding the development of white and brown adipose tissues, as well as pathological conditions such as obesity and diabetes. The robust induction of PPARY expression during adipogenesis also serves as an excellent model system for studying transcriptional and epigenetic regulation of cell-type-specific gene expression.
\end{abstract}

Keywords: PPARY, Adipogenesis, Transcriptional regulation, Enhancer, Epigenetic regulation, Histone acetylation, Histone methylation, Chromatin remodeling

\section{Introduction}

\section{PPARY and adipogenesis}

PPAR $\gamma$ (Peroxisome proliferator-activated receptor $\gamma$ ) is a member of the nuclear receptor superfamily of ligandactivated transcription factors (TFs) [1,2]. It is highly expressed in white and brown adipose tissues (Figure 1). PPARY is considered a master regulator of adipocyte differentiation (adipogenesis) [3]. Ectopic expression of PPARY in non-adipogenic embryonic fibroblasts stimulates the adipocyte gene transcription program and drives adipogenesis [4]. PPARY is essential for adipogenesis, as no single factor has been identified that can drive adipogenesis in the absence of PPAR $[5,6]$. Consistently, PPAR knockout mice lack terminally differentiated adipose tissues and develop fatty liver and lipodystrophy $[7,8]$.

PPAR $\gamma$ is not only critical for adipogenesis but also important for the maintenance of the fully differentiated state both in culture and in mice $[9,10]$. Consistently, mutations of the PPARY gene have been implicated in lipodystrophy as well as other metabolic diseases such as hypertension and insulin resistance in humans [11-13]. Antidiabetic insulin-sensitizing drug thiazolidinediones (TZDs) such as Rosiglitasone have been identified as

\footnotetext{
* Correspondence: kaig@niddk.nih.gov

Adipocyte Biology and Gene Regulation Section, Laboratory of Endocrinology and Receptor Biology, National Institute of Diabetes and Digestive and Kidney Diseases, National Institutes of Health, Bethesda, MD 20892, USA
}

potent and selective ligands of PPAR [14] but these drugs have undesirable side effects [15].

\section{PPARY gene}

The mouse PPARy gene spans over $120 \mathrm{~kb}$ of the genomic sequence on chromosome 6 [16]. It is expressed as two isoforms, PPAR $\gamma 1$ and PPAR $\gamma 2$, as a result of different promoter usage and alternative splicing $[16,17]$. The PPAR 1 promoter is located $60 \mathrm{~kb}$ upstream of the PPAR 2 promoter. PPAR 2 expression is restricted to adipose tissues, while PPARY1 is also expressed in various other tissues. Both PPAR 1 and PPAR 2 are strongly induced during adipogenesis but are differentially regulated. During adipogenesis of the widely used mouse white preadipocyte cell line 3T3-L1, PPAR 1 is induced earlier than PPAR $\gamma 2$ but the two isoforms are expressed at similar levels in the late phase of differentiation [18]. During adipogenesis of mouse brown preadipocytes, PPAR 1 is induced in the early phase and remains the dominant isoform while PPAR $\gamma 2$ is induced relatively late and remains the minor isoform throughout differentiation $[18,19]$. The functional differences of the two PPAR $\gamma$ isoforms in adipogenesis and in mature adipose tissues remain elusive. While the regulation of PPARY expression during adipogenesis has been extensively studied, little is known about the regulation of PPARY expression in non-adipose tissues and cells. 


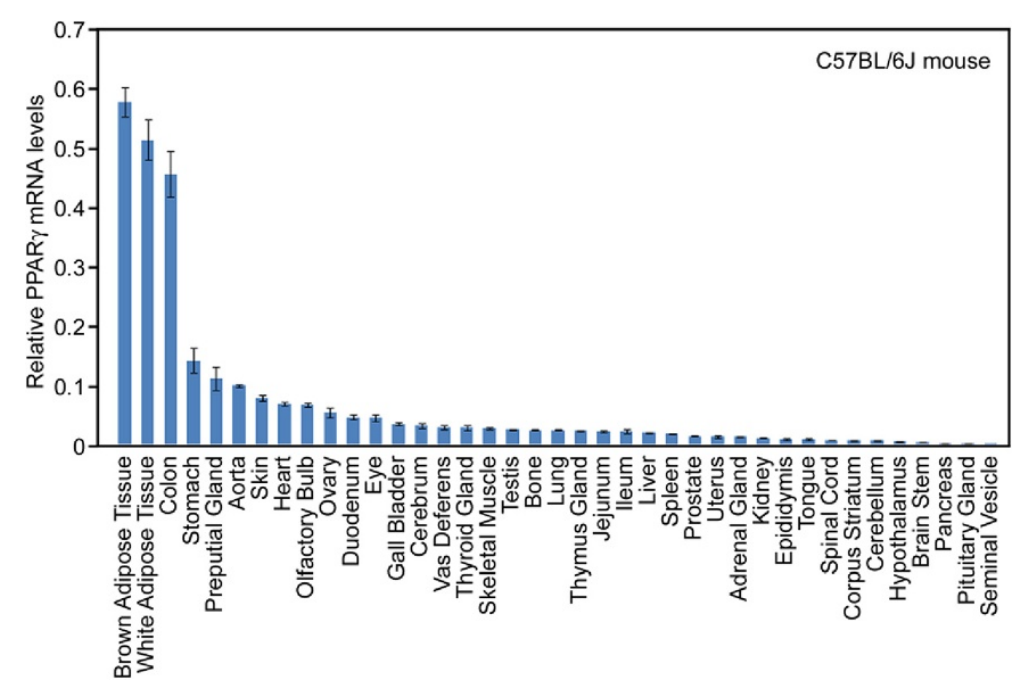

Figure 1 Tissue distribution of PPARY. PPARY is highly expressed in brown and white adipose tissues and colon in C57BL/6 J mice. Quantitative reverse-transcriptase PCR (qRT-PCR) of PPARy mRNA levels in various mouse tissues is shown. The original data was obtained from www.nursa.org/ 10.1621/datasets.02001 and modified.

\section{Epigenetic regulation of gene expression}

Eukaryotic genomes are packaged into chromatin whose basic unit is the nucleosome [20]. The nucleosome consists of a histone octamer of four core histones $(\mathrm{H} 2 \mathrm{~A}$, $\mathrm{H} 2 \mathrm{~B}, \mathrm{H} 3, \mathrm{H} 4)$ wrapped by DNA. The X-ray structure of the nucleosome reveals that histone tails extend outside of the core region [21]. Histone tails are subjected to various covalent modifications (i.e. acetylation, methylation, and phosphorylation), which play important roles in regulating nucleosome structure and recruitment of chromatin-associated proteins [22]. The presence of the nucleosome prevents gene transcription in vitro [23]. Nucleosome occupancy correlates inversely with transcription initiation [24]. Therefore, dynamic changes in nucleosome structure are necessary to achieve gene expression. Chromatin remodeling and histone modification are two major epigenetic mechanisms that alter nucleosome structure to regulate gene expression.

\section{Chromatin remodeling}

Chromatin represses transcription by blocking protein access to the DNA template. Therefore, DNA binding of TFs and transcription cofactors often occurs concurrently with chromatin structure alteration by chromatin remodeling complexes [25]. Two major types of chromatin remodeling complexes have been identified-SWI/SNF and ISWI, both of which contain the ATPase subunit. SWI/SNF complexes disrupt nucleosome core conformation by altering the histone-DNA binding [26]. On the other hand, ISWI complexes promote nucleosome sliding without displacing the histone octamer from DNA [27]. Despite the mechanistic differences, both complexes use the energy from ATP hydrolysis to change nucleosome conformation or location [25].

\section{Histone modification}

Histones, particularly their N-terminal tails, are covalently modified at many lysine $(\mathrm{K})$ or arginine $(\mathrm{R})$ residues [28]. The combination of covalent modifications affects chromatin structure and gene expression [29]. Acetylation and methylation are two types of extensively studied histone modifications. Histone acetylation is generally correlated with gene activation although it remains to be determined whether a specific histone acetylation is a cause or consequence of gene activation [30]. Acetylation on histones is written by histone acetyltransferases (HATs) and erased by histone deacetylases (HDACs) [31,32]. Recent publications suggest that HATs are highly site-specific in mammalian cells $[30,33,34]$

Genome-wide profiling by ChIP-Seq reveals that histone methylation correlates with gene activation or repression depending on the methylation sites and states (me1, me 2 and me3, i.e. mono-, di- and tri-methylation) $[35,36]$. Methylation of $\mathrm{K} 4, \mathrm{~K} 36, \mathrm{~K} 79$ on histone H3 (H3K4, H3K36, H3K79) correlates with gene activation, whereas di-methylation of $\mathrm{K} 9$ or tri-methylation of $\mathrm{K} 27$ on $\mathrm{H} 3$ (H3K9me2 or H3K27me3) correlate with gene repression. Each modification shows a distinct profile along the genome. For example, tri-methylation on H3K4 (H3K4me3) usually occurs at promoters of actively transcribed genes [37]. Promoter-distal mono- and dimethylation of H3K4 (H3K4me1/2) mark enhancers [38]. Tri-methylation of H3K36 (H3K36me3) associates with elongating RNA polymerase II (Pol II) and is thus 
enriched on the gene body with peaks at the 3' end of transcribed regions [35].

Histone methylations are dynamically regulated by remarkably site-specific methyltransferases and demethylases. Histone methyltransferases for H3K4, H3K9, H3K27, H3K36 and H3K79, as well as histone demethylases for H3K4, H3K9, H3K27 and H3K36, have been identified $[39,40]$. However, their biological functions are largely unclear.

\section{Transcriptional regulation of PPAR $\gamma$ expression during adipogenesis}

A good number of TFs have been reported to positively or negatively regulate adipogenesis and PPARY expression (Figure 2) $[5,6]$. However, whether these factors directly regulate PPARy expression is often unclear.

\section{Positive regulators of PPARY expression}

Pro-adipogenic TFs promote adipogenesis in part by directly or indirectly up-regulating PPARY expression or by stimulating PPAR $\gamma$ transcriptional activity. Here, we focus on the factors that have been shown to bind the $P P A R \gamma$ gene locus and/or activate the PPARY promoter in reporter assays. It is likely that these factors regulate PPARy expression directly.

\section{CCAAT/enhancer-binding proteins (C/EBPs)}

C/EBPs, including C/EBP $\alpha, \beta$ and $\delta$, are basic leucine zipper family TFs that are crucial for adipogenesis $[6,41]$. C/EBPs form homo- and hetero-dimers to bind to their consensus sequences on target genes [42]. In the early phase of adipogenesis, $\mathrm{C} / \mathrm{EBP} \beta$ and $\mathrm{C} / \mathrm{EBP} \delta$ are induced immediately by adipogenic chemicals isobutylmethylxanthine (IBMX) and dexamethasone (DEX), respectively [43]. Ectopic expression of C/EBP $\beta$ alone or together with C/EBP $\delta$ induces PPARY expression in non-adipogenic NIH3T3 fibroblasts $[44,45]$. Conversely, double knockout of $C / E B P \beta$ and $C / E B P \delta$ in mice reduces adipose tissue

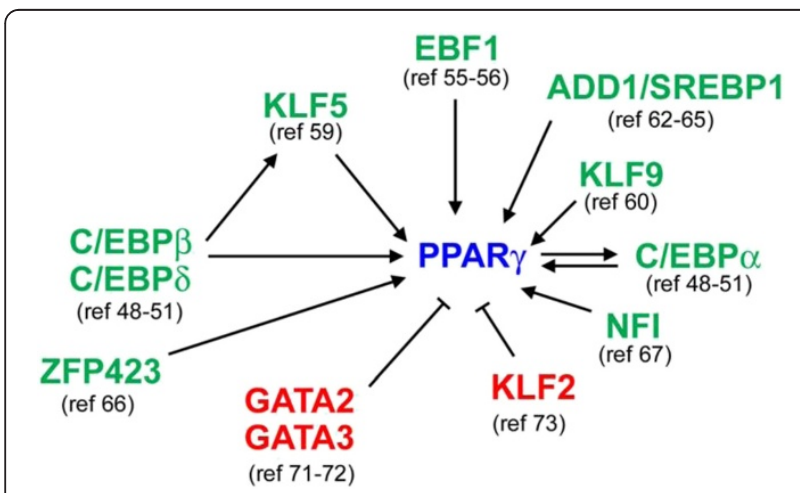

Figure 2 Transcriptional regulation of PPARY expression during adipogenesis. PPARY expression is regulated by multiple positive and negative transcription factors (TFs) as well as signaling pathways. weight [46]. C/EBP $\alpha$ is another adipogenic TF and is both necessary and sufficient for adipogenesis [6,41]. C/EBP $\alpha$ expression is induced relatively late around day $2-4$ during adipogenesis of L1 cells. C/EBP $\alpha$ knockout mice lack white adipose tissue and show reduced brown adipose tissue [47].

The mouse PPARy2 promoter contains two C/EBP recognition elements at $-340 \mathrm{bp}$ and $-327 \mathrm{bp}$ from the transcription start site [16]. While all three C/EBPs can bind directly to these elements and induce PPAR 2 expression, C/EBP $\alpha$ binding replaces early C/EBPs at later stages, which is consistent with their expression patterns $[48,49]$. ChIP-Seq analyses show that C/EBP $\alpha, C / E B P \beta$ and PPAR $\gamma$ also bind to enhancer-like regions in the $3^{\prime}$ of the PPARY gene locus [50].

Recent ChIP-Seq analyses reveal that C/EBP $\beta$ functions as a pioneer TF in the early phase of adipogenesis [51]. Once C/EBP $\beta$ binds to adipogenic enhancer regions (also known as "hotspots"), which can also be found on $P P A R \gamma$ and C/EBPa gene loci, it facilitates the recruitment of other adipogenic TFs such as glucocorticoid receptor (GR), STAT5A and RXR to form adipogenic enhancers and consequently induces expression of late acting TFs such as PPAR $\gamma$ and C/EBP [52]. As a pioneer adipogenic TF, C/EBP $\beta$ recruits $\mathrm{H} 3 \mathrm{~K} 4$ mono- and dimethyltransferase MLL4 to establish a subset of active adipogenic enhancers during adipogenesis, including the ones on the PPARY gene locus [50].

\section{Early B-cell factors (EBFs)}

EBF1 is one of the critical $B$ cell fate determining factors [53]. EBF2 is known to regulate osteoclast differentiation [54]. Both EBF1 and EBF2 are also induced during adipogenesis of 3T3-L1 white preadipocytes but with different expression patterns [55]. Ectopic expression of either factor in NIH3T3 fibroblasts promotes adipogenesis $[55,56]$.

EBF2 is expressed at higher levels in brown compared to white adipose tissues. It has been shown that EBF2 regulates brown adipocyte-specific Ucpland Prdm16 expression [57]. Although knockout of the EBF2 gene in mice does not affect PPARY expression, there might be potential redundancy between EBF1 and EBF2. Our unpublished data suggests that EBF2 directly binds to the PPARY gene locus during brown adipogenesis.

The EBF binding motif is highly enriched in active enhancers of adipogenesis and in brown adipose tissuespecific PPAR $\gamma$ binding sites [50,57]. EBF1 binds to PPAR 1 promoter with the strongest binding at $1 \mathrm{~h}$, suggesting that EBF1 is one of the early regulators of PPARY expression [55]. Future studies are needed to identify the genomic binding profiles of EBF family members during white and brown adipogenesis. The functional redundancy and specificity of EBF family members in regulation of PPARY expression and adipogenesis also need to be clarified. 


\section{Krüppel-like factors (KLFs)}

Several members of KLF family of zinc-finger TFs, including KLF4, KLF5, KLF9 and KLF15, are induced at various stages of $3 \mathrm{~T} 3-\mathrm{L} 1$ adipogenesis. KLF4 and KLF5 mRNA levels are induced in the early phase of adipogenesis and peak at around $2 \mathrm{~h}$ and $6 \mathrm{~h}$, respectively [58,59]. KLF9 and KLF15 mRNA levels are induced at day 2-4 of 3T3-L1 adipogenesis and peak at around day 6-8 [60,61].

Individual knockdown of KLF4, KLF5, KLF9 and KLF15 has been shown to block adipogenesis of 3 T3-L1 preadipocytes, suggesting that these four KLFs play positive roles in adipogenesis [58-61]. Among them, KLF5 and KLF9 have been shown to directly bind to the PPAR 2 promoter. KLF5 binds from $-340 \mathrm{bp}$ to $-260 \mathrm{bp}$ of the PPAR 2 promoter and cooperates with C/EBPs to induce PPARY2 expression [59]. KLF9 binds from -413 bp to $-247 \mathrm{bp}$ of the PPAR 2 promoter and moderately activates the $P P A R \gamma 2$ promoter in a luciferase reporter assay [60]. Thus, KLF5 and KLF9 show distinct expression patterns during adipogenesis but appear to share the same region on $P P A R \gamma 2$ promoter. To understand the mechanisms by which KLFs regulate adipogenesis and PPARy expression, the genomic binding profiles of KLFs during adipogenesis need to be determined. The functional redundancy and specificity of KLFs in regulation of adipogenesis and PPAR $\gamma$ expression also need to be clarified.

Unlike the KLFs mentioned above, KLF2 has been reported to inhibit PPARy expression and will be discussed in a later section [62].

\section{Sterol regulatory element-binding protein-1 (SREBP1)}

SREBP1 (also known as ADD-1; adipocyte determination and differentiation factor 1) is a basic helix-loop-helix leucine zipper TF involved in cholesterol homeostasis [63]. It is expressed in various tissue types with the highest level in brown adipose tissue [64]. SREBP1 is induced during differentiation of 3T3-F442 and 3T3-L1 preadipocytes. A dominant-negative form of SREBP1 with a mutation in the DNA-binding domain markedly inhibits adipogenesis of 3T3-L1 cells [65]. Ectopic expression of SREBP1 induces endogenous PPARy expression in 3T3L1 and HepG2 cells. SREBP1 has been shown to bind to a putative E-box motif at -1535 bp of the PPAR 1 promoter, and mutation of this motif inhibits SREBP1 binding [66]. To understand how SREBP1 regulates PPARy expression and adipogenesis, it will be critical to determine the genomic binding profile of SREBP1 during adipogenesis.

\section{Zinc finger protein 423 (ZFP423)}

ZFP423 is a zinc finger TF and was recently identified as a preadipocyte determination factor [67]. It is enriched in preadipocytes compared to non-adipogenic fibroblasts and its expression levels positively correlate with the adipogenic potential of fibroblasts. Ectopic expression of ZFP423 in non-adipogenic NIH3T3 fibroblasts induces $P P A R \gamma 2$ but not PPARY1 expression before differentiation and promotes adipogenesis after induction of differentiation. Conversely, knockdown of ZFP423 in 3T3L1 preadipocytes blocks adipogenesis and decreases both PPARY1 and PPAR 2 levels before and after differentiation [67]. However, the molecular mechanism by which ZFP423 regulates PPARy expression remains incompletely understood.

\section{Nuclear factor I (NFI)}

The NFI family TFs were identified as potential novel regulators of adipogenesis from computational motif analysis of adipocyte-specific open chromatin regions in 3T3-L1 cells [68]. The NFI binding motif also shows up in other studies involving epigenomic profiling of adipogenesis [50,57]. During adipogenesis, NFIA and NFIB expression levels are significantly induced while NFIC and NFIX levels remain steady. Knockdown of either NFIA or NFIB reduces the differentiation ability of 3T3L1. ChIP analysis reveals binding of NFIA to known distal regulatory elements of $P P A R \gamma$ and $C / E B P \alpha$, as well as Fabp4 genes [68].

\section{Positive cross-regulation between PPAR $y$ and C/EBPa}

PPAR $\gamma$ and C/EBP $\alpha$ positively regulate each other's expression and cooperate to promote adipogenesis $[3,69]$. PPAR $\gamma$ is essential for $\mathrm{C} / \mathrm{EBP} \alpha$-stimulated adipogenesis in fibroblasts [3]. Conversely, $C / E B P \alpha$ knockout fibroblasts show severe defects in PPAR $\gamma$-stimulated adipogenesis in the absence of synthetic PPAR $\gamma$ ligands and partial defects in the presence of these ligands, suggesting that $\mathrm{C} / \mathrm{EBP} \alpha$ is also required for PPAR $\gamma$-stimulated adipogenesis [19]. PPAR $\gamma$ directly activates endogenous $C / E B P \alpha$ gene transcription. Once induced, $\mathrm{C} / \mathrm{EBP} \alpha$ binds to the $P P A R y$ gene locus and further induces and maintains $P P A R y$ expression in mature adipocytes through a positive feedback loop [3]. Genome-wide profiling studies show that during adipogenesis, most induced genes are bound by both PPAR $\gamma$ and $\mathrm{C} / \mathrm{EBP} \alpha$, suggesting a synergistic upregulation of adipogenic gene expression by these two master regulators [70,71]. Interestingly, PPAR $\gamma$ binds its own gene locus, where $\mathrm{C} / \mathrm{EBP} \alpha$ also binds (Figure 3 ). These regions include the $P P A R \gamma 2$ promoter and downstream intergenic enhancer regions [50].

\section{Negative regulators of PPARY expression GATAs}

Of the six GATA family zinc finger domain TFs, GATA2 and GATA-3 are highly expressed in the preadipocyte fraction of white adipose tissues in mice. Their expression is down-regulated during differentiation of 3T3- 


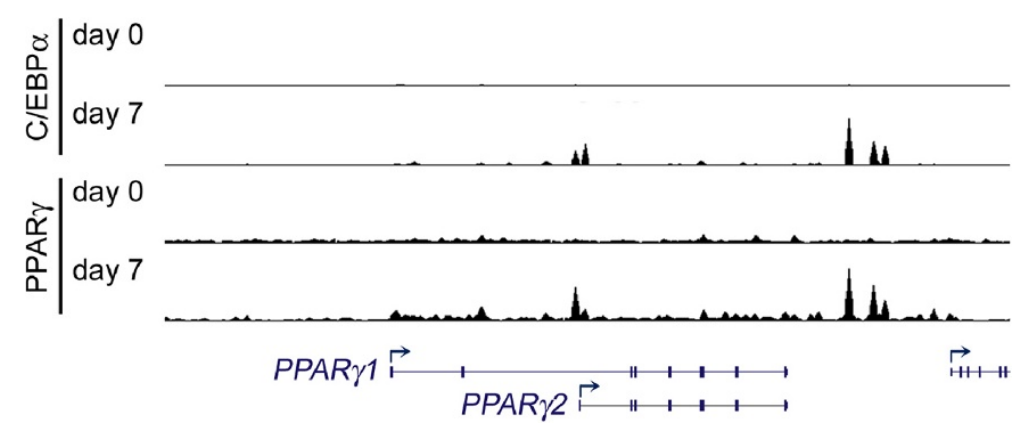

Figure 3 Co-localization of PPARY and C/EBPa on PPARY gene locus during adipogenesis. Snapshot of PPARY and C/EBPa binding profiles on the PPARY gene locus during brown adipogenesis. ChIP-Seq of PPARY and C/EBPa were performed before (day 0) and after (day 7) differentiation of immortalized brown preadipocytes (unpublished). Enrichment of peaks was visualized in the UCSC genome browser.

F442A preadipocytes. Constitutive expression of GATA2 or GATA-3 inhibits 3T3-F442A differentiation and PPARy expression. Consistently, GATA-3 knockout ES cells show enhanced ability of differentiation towards adipocytes. In a luciferase reporter assay, GATA-2 and GATA-3 inhibit the activity of $0.6-\mathrm{kb} P P A R \gamma 2$ proximal promoter [72]. GATA-2 and GATA-3 are also found to inhibit the transcriptional activities of $\mathrm{C} / \mathrm{EBP} \alpha$ and $\mathrm{C} /$ $\mathrm{EBP} \beta$ through physical interactions, thus offering an additional mechanism by which GATA-2/3 inhibit adipogenesis and $P P A R \gamma$ expression [73]. It remains to be determined whether GATA-2/3 directly repress $P P A R \gamma$ expression in preadipocytes.

\section{KLF2}

Overexpression of KLF2 strongly inhibits differentiation of 3T3-L1 preadipocytes and the expression of $P P A R \gamma$ but not the early adipogenic TFs $C / E B P \beta$ and $C / E B P \delta$. KLF2 can directly bind to the CACCC element within the $P P A R \gamma 2$ proximal promoter region and repress $P P A R \gamma 2$ promoter activity in a reporter assay. However, mutation of its binding site alone is insufficient to block KLF2-mediated repression of the PPAR 2 promoter, suggesting that other mechanisms are also involved [62]. It remains to be determined whether endogenous KLF2 directly represses $P P A R \gamma$ expression in preadipocytes.

\section{Epigenetic regulation of PPARY expression during adipogenesis}

$P P A R Y$ expression during adipogenesis is regulated by chromatin remodeling and histone modifications such as acetylation and methylation (Figure 4).

\section{Chromatin remodeling}

The PPARy gene locus undergoes dynamic changes within hours of adipogenesis induction. DNase I hypersensitivity assays reveal that chromatin remodeling and opening of the PPAR $\gamma$ gene locus occur within 3-4 hours of induction in 3T3-L1 cells [51]. The major opening regions are the PPAR 2 promoter and 3' distal regions that are occupied by $\mathrm{C} / \mathrm{EBP} \beta, \mathrm{C} / \mathrm{EBP} \alpha$, and PPAR $\gamma$ itself in later stages of differentiation [50].

Chromatin remodeling and opening at the PPAR 2 promoter are adipose-specific and dependent on CAMP and protein kinase A (PKA) pathways [74]. IBMX alone can induce chromatin opening of the $P P A R \gamma 2$ promoter. Conversely, shRNA-mediated knockdown of PKA subunits inhibits chromatin accessibility of the $P P A R \gamma 2$ promoter region.

The SWI/SNF chromatin remodeling complex has been shown to regulate $P P A R \gamma 2$ expression during adipogenesis

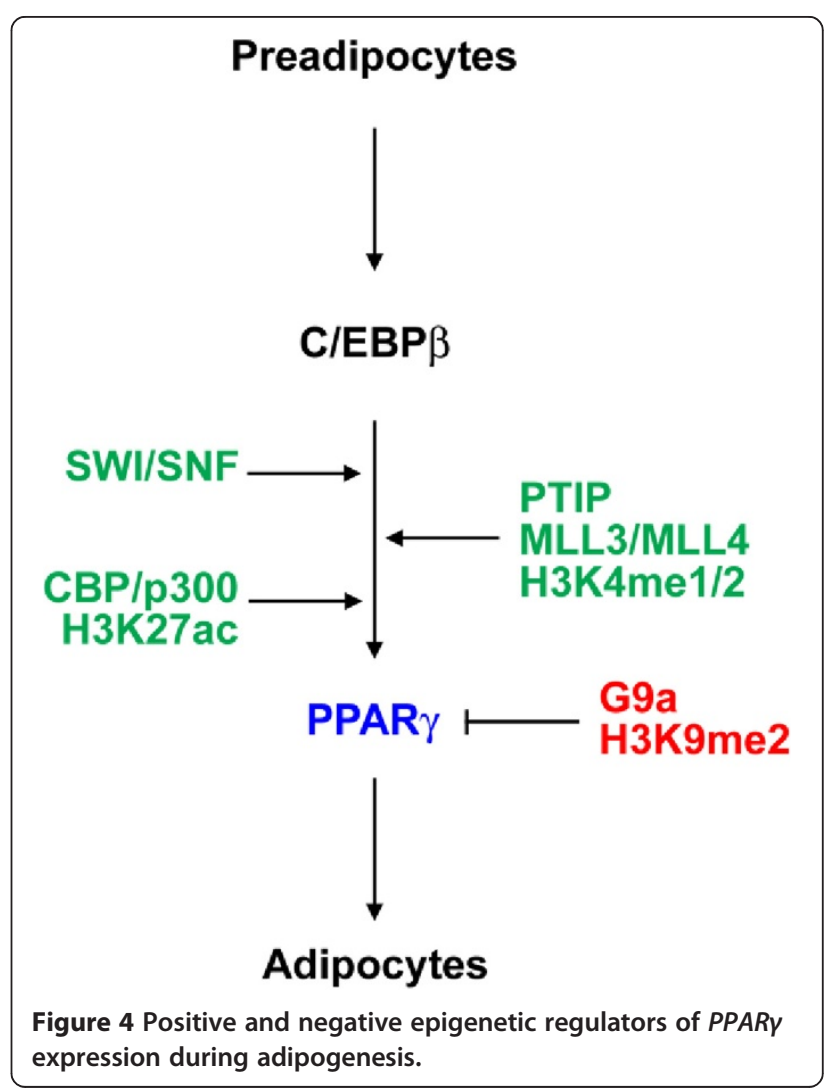


[75]. The dominant-negative form of Brg1, an ATPase subunit of the SWI/SNF complex, inhibits PPAR $\gamma^{-}, \mathrm{C} / \mathrm{EBP} \alpha-$, or $\mathrm{C} / \mathrm{EBP} \beta$-induced adipogenesis in fibroblasts. In the early stage of 3T3-L1 differentiation, C/EBP factors bind to the PPARy2 promoter, followed by Pol II and general TFs assembly prior to and independently of SWI/SNF. SWI/SNF and TFIIH then assemble on the PPAR 2 promoter to facilitate preinitiation complex formation. It remains unclear how the SWI/SNF complex is recruited to the PPARY gene locus.

\section{Histone acetylation}

Histone acetylations generally correlate with gene activation and are catalyzed by site-specific histone acetyltransferases (HATs). In mammalian cells, the homologous and functionally redundant HATs GCN5 and PCAF specifically acetylate $\mathrm{H} 3 \mathrm{~K} 9$, while another pair of homologous and functionally redundant HATs CBP and p300 specifically acetylates H3K18 and H3K27 [30].

Genome-wide profiling of $\mathrm{H} 3 \mathrm{~K} 9 \mathrm{ac}$ and $\mathrm{H} 3 \mathrm{~K} 27 \mathrm{ac}$ reveals that both marks are highly induced on the PPAR gene locus during 3T3-L1 differentiation and correlate with $P P A R y$ gene expression [76,77]. While the roles of GCN5/PCAF and GCN5/PCAF-mediated H3K9ac in regulating $P P A R y$ expression and adipogenesis remain to be determined, $\mathrm{CBP} / \mathrm{p} 300$ are known to be essential for adipogenesis and PPARY expression [78]. CBP/p300mediated H3K27ac is a marker for active enhancers and therefore highly associates with cell type-specific gene expression [79]. ChIP-Seq of H3K27ac has revealed adipose-specific active enhancers located in the intergenic regions downstream of the PPAR $\gamma$ gene (Figure 5) [50]. The functional roles of these enhancers in regulating $P P A R y$ expression during adipogenesis remain to be examined.

HBO1, also known as MYST2 or KAT7, is a member of the MYST family of HATs. It is specifically required for H3K14ac in mammalian cells [34]. Another member of the MYST family of HATs, MOF (also known as MYST1 or KAT8), is specifically required for H4K16ac in mammalian cells [80]. Both H3K14ac and H4K16ac positively correlate with gene expression. However, the roles of $\mathrm{HBO} 1$-mediated $\mathrm{H} 3 \mathrm{~K} 14 \mathrm{ac}$ and MOF-mediated H4K16ac in regulating PPARY expression and adipogenesis remain to be determined.

\section{Histone methylation}

Several histone methyltransferases and demethylases have been shown to regulate adipogenesis [19,39,50,81-83]. Among them, H3K4 mono- and di-methyltransferases MLL3 (KMT2C) and MLL4 (KMT2D) directly promote $P P A R y$ expression during adipogenesis [50]. In contrast, H3K9 mono- and di-methyltransferase G9a (EHMT2) directly represses $P P A R \gamma$ expression in preadipocytes and during adipogenesis [81]. While H3K27 methyltransferase Ezh2 directly represses Wnt genes to facilitate adipogenesis, Ezh2 and Ezh2-mediated Н3K27me3 are absent from the PPARY gene locus during adipogenesis and thus promote $P P A R y$ expression indirectly [83].

\section{H3K4 methyltransferases MLL3/MLL4 directly promote PPARY expression}

Homologous MLL3 and MLL4 belong to the mammalian SET1-like H3K4 methyltransferase family [84-86]. Each member of this family of six methyltransferases forms a large protein complex that contains WDR5, RbBP5, ASH2L, and DPY30 (WRAD) subunits [84-87]. In addition to the common WRAD subunits, MLL3/MLL4 complexes also contain unique subunits, including H3K27 demethylase UTX, nuclear receptor coactivator NCOA6, BRCT domain-containing protein PTIP, and a novel protein PA1 (also known as PAGR1) [84,88-90].

Enhancers control cell-type-specific gene expression and are marked with $\mathrm{H} 3 \mathrm{~K} 4 \mathrm{me} 1 / 2$ [38]. We recently showed that MLL3 and MLL4 are major H3K4 monoand di-methyltransferases in human and mouse cells. ChIP-Seq analyses reveal that MLL4 shows cell-typeand differentiation-stage-specific genomic binding and is mainly enriched on active enhancers during cell differentiation. MLL3 and MLL4 are partially redundant and are major H3K4 mono- and di-methyltransferases on enhancers. Using adipogenesis and myogenesis as model systems, we showed that MLL3 and MLL4 are required for enhancer activation, cell-type-specific gene induction and cell differentiation [50].

MLL3 and MLL4 have partially overlapping functions and are essential for PPAR $y$ expression and adipogenesis [50]. During adipogenesis, MLL4 is mainly enriched on adipogenic enhancers, which are active enhancers bound by PPAR $\gamma, \mathrm{C} / \mathrm{EBP} \alpha$ and $\mathrm{C} / \mathrm{EBP} \beta$. MLL4 physically interacts with $\mathrm{C} / \mathrm{EBP} \beta$ and PPAR $\gamma$ in cells. In the early phase of adipogenesis, the pioneer adipogenic TF $C / E B P \beta$ recruits MLL4 to perform H3K4me1/2 and establish adipogenic enhancers on gene loci encoding the master adipogenic TFs PPAR $\gamma$ (Figure 5) and C/EBP $\alpha$. After PPAR $\gamma$ and $\mathrm{C} / \mathrm{EBP} \alpha$ are induced, they recruit MLL4 to perform H3K4me1/2 and establish enhancers critical for adipocyte gene expression. Deletion of MLL3 and MLL4 in preadipocytes prevents the activation of adipogenic enhancers on PPAR $\gamma$ and $C / E B P \alpha$ genes, as well as their induction, which lead to severe defects in adipogenesis [50]. MLL4 appears to be the major regulator of adipogenesis in mice with MLL3 playing a minor role [50,91]. Knockout of MLL4 by muscle- and brown adipose tissue (BAT)-selective Myf5-Cre in mice inhibits normal development of Myf5+ muscles and BAT.

MLL3/MLL4-associated NCOA6 and PTIP have also been shown to be important for adipogenesis, although 

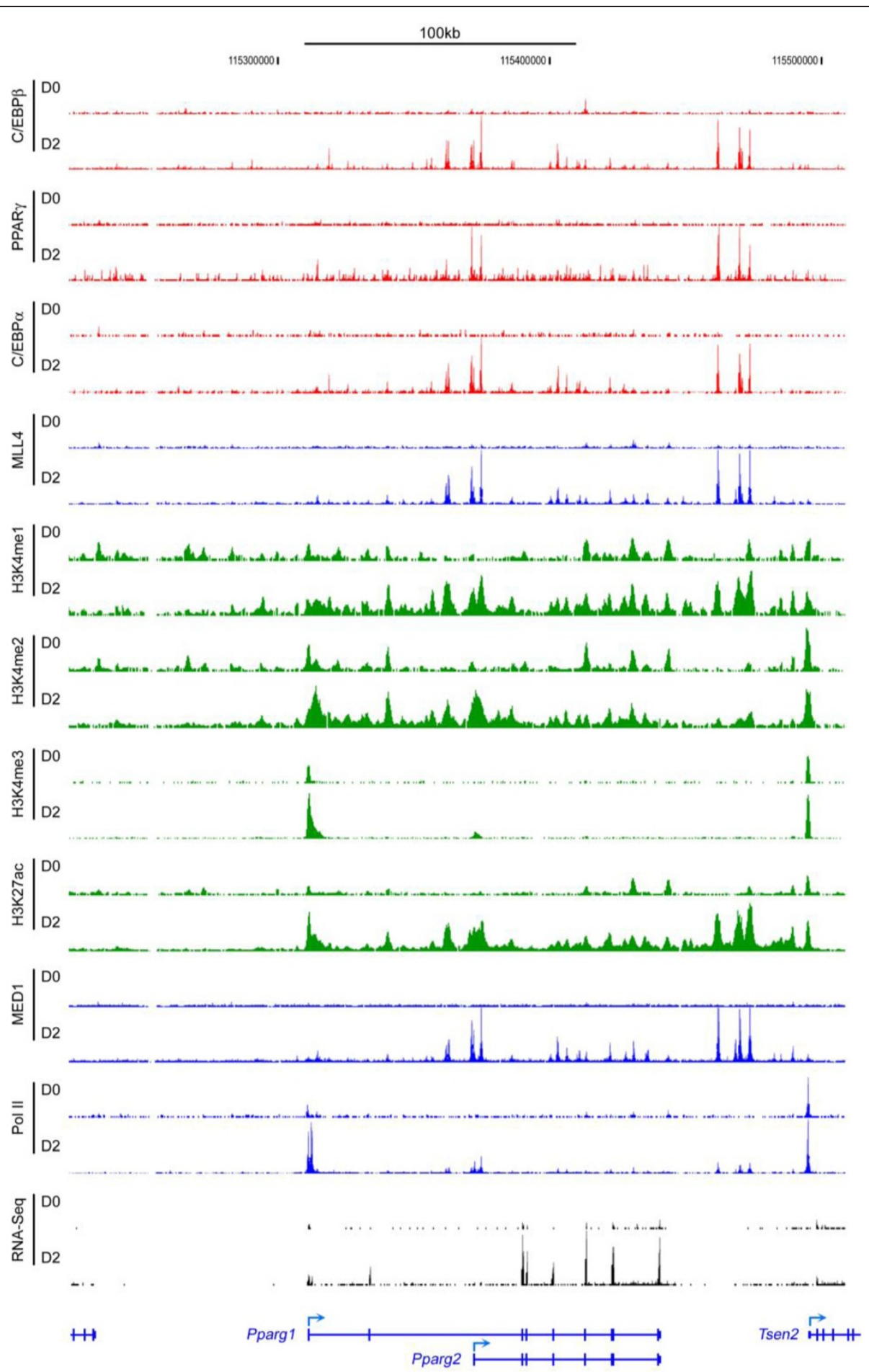

Figure 5 ChIP-Seq and RNA-Seq profiles on PPARY gene locus during adipogenesis. ChIP-Seq and RNA-Seq were performed during brown preadipocyte differentiation. The original sequencing data was obtained from NCBI GEO database (http://www.ncbi.n/m.nih.gov/geo/) under accession number GSE50466 [50].

the underlying molecular mechanisms are unclear $[19,92]$. PTIP is a nuclear protein with functions in transcription and DNA damage response. PTIP directly controls the induction of $P P A R \gamma$ and $C / E B P \alpha$ during adipogenesis and is required for the enrichment of MLL3/MLL4 complexes on the PPAR $\gamma$ promoter region [19]. Since PTIP itself does not possess a DNA binding domain, PTIP may function through MLL3/MLL4 to 
help establish adipogenic enhancers. This hypothesis can be tested by performing ChIP-Seq of PTIP in MLL3/ MLL4 knockout cells and vice versa.

\section{H3K9 methyltransferase G9a directly represses PPARY expression}

H3K9me2 and H3K27me3 are two major repressive epigenetic marks. G9a is the major methyltransferase responsible for H3K9me2 while Ezh2 is the major methyltransferase responsible for H3K27me3 in cells [93-95]. ChIP-Seq reveals that the genomic locations of H3K9me2 and H3K27me3 are largely non-overlapping in preadipocytes [81]. On gene loci encoding the major negative and positive regulators of adipogenesis, Wnt gene loci are marked with high levels of H3K27me3 but little H3K9me2. In contrast, the entire PPARY gene locus is covered with high levels of $\mathrm{H} 3 \mathrm{~K} 9 \mathrm{me} 2$ but little H3K27me3. H3K9me2 levels are also low on gene loci encoding other positive regulators of adipogenesis, including C/EBPs, KLF4, Krox20 and CREB. During adipogenesis, H3K9me2 levels and G9a protein levels decrease significantly. Deletion of G9a in preadipocytes or inhibition of G9a methyltransferase activity increases $P P A R \gamma$ expression and adipogenesis by promoting $\mathrm{C} /$ EBP $\beta$ binding to and chromatin opening of the $P P A R \gamma$ gene locus [81].

The inverse correlation between the genomic locations of $\mathrm{H} 3 \mathrm{~K} 9 \mathrm{me} 2$ and $\mathrm{H} 3 \mathrm{~K} 27 \mathrm{me} 3$ in preadipocytes suggests that G9a-mediated $\mathrm{H} 3 \mathrm{~K} 9 \mathrm{me} 2$ is a major repressive epigenetic mechanism that regulates $P P A R \gamma$ expression in the early phase of adipogenesis. The marked decrease of H3K9me2 on the entire PPARY gene locus during adipogenesis suggests that $\mathrm{H} 3 \mathrm{~K} 9 \mathrm{me} 2$ demethylases may antagonize G9a function. Among the known H3K9 demethylases [39], it is currently unknown which H3K9 demethylases remove H3K9me2 on the PPARY gene locus during adipogenesis.

\section{Future directions}

In addition to identifying novel regulators of $P P A R \gamma$ expression during adipogenesis, future studies should at least address the following issues: i) distinguishing direct vs. indirect regulators of the $P P A R \gamma$ gene, ii) characterizing of putative $P P A R \gamma$ enhancers, iii) understanding the mechanisms by which epigenetic regulators are recruited to the $P P A R Y$ gene locus, and iv) determining of chromatin interaction of the PPAR gene locus.

Distinguishing direct vs. indirect regulators of PPAR $\gamma$ gene A good number of TFs and epigenetic factors have been shown to modulate adipogenesis and the associated PPARY expression [96]. However, it is largely unclear whether these factors directly or indirectly regulate the PPARY gene. Genome-wide profiling by ChIP-Seq has made it possible to map genomic binding sites of these factors and to distinguish direct vs. indirect regulators of $P P A R y$ expression during adipogenesis in an unbiased way. Genome-wide binding profiles of PPAR $\gamma, \mathrm{C} / \mathrm{EBP} \alpha$, $\mathrm{C} / \mathrm{EBP} \beta$ during adipogenesis have been generated $[50,68,70,71,76]$. The genomic binding sites of other adipogenic TFs including EBFs, KLFs, SREBP1, ZFP423 and NFI, as well as the genomic binding sites of negative regulators of $P P A R \gamma$ expression and adipogenesis including GATA2/3 and KLF2, need to be determined using ChIP-Seq.

\section{Characterization of putative PPAR $\gamma$ enhancers}

Enhancers regulate cell-type-specific gene expression and promote gene transcription by delivering necessary factors to the promoters. The interaction between enhancers and promoters is critical for cell-type-specific gene transcriptional programs [38]. Therefore, identifying cell-type-specific enhancers is important for understanding the mechanisms that control the expression of developmental genes. ChIP-Seq profiling of adipogenic TFs PPAR $\gamma$ and $\mathrm{C} / \mathrm{EBP} \alpha / \beta$, enhancer marks H3K4me1/2 and the H3K4me1/2 methyltransferase MLL4, as well as active enhancer mark H3K27ac, has enabled the identification of putative adipocyte-specific enhancers in the intergenic region downstream of $P P A R \gamma$ gene (Figures 3 and 5).

The next step is to characterize and validate these putative $P P A R y$ enhancers. The traditional luciferase reporter assay is easy to perform but has several limitations [97]. First, the enhancer DNA sequence cloned into the luciferase reporter plasmid lacks the native chromatin structure and therefore may not be representative of the physiological enhancer. Second, most genes are regulated by multiple enhancers, but only one enhancer can be tested in a reporter assay. The recently developed genome editing technique CRISPR could be a better approach [98]. This method can be used to disrupt $P P A R y$ enhancers in preadipocytes to validate their functional importance in regulating $P P A R \gamma$ expression during adipogenesis.

\section{How are epigenetic factors recruited to the PPAR $\gamma$ gene locus?}

Sequence-specific TFs likely play a major role in the recruitment of epigenetic factors to target gene loci because most epigenetic regulators lack DNA-binding domains. For example, the MLL3/MLL4 complexes physically interact with PPAR $\gamma$ and C/EBP $\beta[50,91]$. Ectopic expression of $\mathrm{C} / \mathrm{EBP} \beta$ alone in undifferentiated preadipocytes is sufficient to recruit MLL4, MLL4mediated H3K4me1, and active enhancer mark H3K27ac to a subset of enhancers on the PPARY gene locus. This suggests that $\mathrm{C} / \mathrm{EBP} \beta$, likely in cooperation with PPAR $\gamma$ 
and C/EBP $\alpha$, recruits the MLL4 complex to establish active PPARy enhancers to promote PPARy expression during adipogenesis. The factors that recruit H3K9 methyltransferase G9a to directly repress PPARY gene remain to be identified.

Recent studies suggest that long intergenic noncoding RNAs (lncRNAs) can mediate the interactions between epigenetic regulator with genome or with other epigenetic regulators $[99,100]$. Expression of several lncRNAs is strongly induced during adipogenesis [101]. Whether any of these lncRNAs directly regulates PPARY expression remains to be determined.

\section{Chromatin interaction of PPARY gene locus}

Physical interaction between distal enhancers and the gene promoter is critical for active gene expression, as shown on the $\beta$-globin locus [102]. Development of the chromosome conformation capture (3C) assay has enabled the identification of long range chromatin interactions [103]. The limitation of $3 \mathrm{C}$ is that we can only see a very narrow region of interest [104]. Updated versions of this technique including $4 \mathrm{C}$ and $5 \mathrm{C}$ assays involve high-throughput sequencing and therefore provide an unbiased picture of chromatin interaction in given cell types. So far, no study has reported the chromatin interaction of PPARY gene locus and its role in regulation of PPARY expression.

In summary, PPARY expression during adipogenesis provides an excellent model system for understanding the transcriptional and epigenetic regulation of cell-typespecific gene transcription programs and cell differentiation. One of our big challenges is to validate the function of regulatory elements outside of the coding region and identify associated factors and $3 \mathrm{D}$ genome structure around the PPARY locus. Such information would be of great help to understanding adipose-related human metabolic diseases, particularly obesity and type II diabetes.

\footnotetext{
Abbreviations

CAMP: Cyclic 3',5'-adenosine monophosphate; CBP: CREB-binding protein; C/EBP: CCAAT/enhancer-binding protein; ChIP-Seq: Chromatin immunoprecipitation sequencing; DEX: Dexamethasone; EBF: Early B-cell factor; EHMT2: Euchromatic histone-lysine N-methyltransferase 2; Ezh2: Enhancer of zeste homolog 2; GATA: GATA-binding protein; GCN5: General control of amino acid synthesis protein 5-like 2; KLFs: Krüppel-like factors; HAT: Histone acetyltransferase; HDAC: Histone deacetylase; IBMX: Isobutylmethylxanthine; KMT: Lysine-specific methyltransferase; MLL3/ 4: Myeloid/lymphoid or mixed-lineage leukemia 3/4; PA1: PTIP-associated 1 protein; PCAF: p300/CBP-associated factor; PKA: Protein kinase A; PPARY: Peroxisome proliferator-activated receptor $\gamma$; PTIP: PAX transactivation domaininteracting protein; ISWI: Immitation of switch; SREBP1: Sterol regulatory element-binding protein-1; NCOA6: Nuclear receptor coactivator 6; NFI: Nuclear factor I; SWI/SNF: Switch/Sucrose nonfermenting; TF: Transcription factor; WDR5: WD repeat-containing protein 5; ZFP423: Zinc finger protein 423.
}

\section{Competing interests}

The authors declare that they have no competing interests.

\section{Authors' contributions}

J-EL carried out the molecular genetic studies, drafted and revised the manuscript. KG drafted and revised the manuscript. Both authors read and approved the final manuscript. This research was supported by the Intramural Research Program of the $\mathrm{NIH}$, The National Institute of Diabetes and Digestive and Kidney Diseases (NIDDK).

Received: 8 April 2014 Accepted: 16 May 2014

Published: 29 May 2014

\section{References}

1. Evans RM, Barish GD, Wang YX: PPARs and the complex journey to obesity. Nat Med 2004, 10(4):355-361.

2. Rosen ED, Spiegelman BM: PPARgamma: a nuclear regulator of metabolism, differentiation, and cell growth. J Biol Chem 2001, 276(41):37731-37734.

3. Rosen ED, Hsu C-H, Wang X, Sakai S, Freeman MW, Gonzalez FJ, Spiegelman BM: C/EBPalpha induces adipogenesis through PPARgamma: a unified pathway. Genes Dev 2002, 16(1):22-26.

4. Tontonoz P, Hu E, Spiegelman BM: Stimulation of adipogenesis in fibroblasts by PPAR gamma 2, a lipid-activated transcription factor. Cell 1994, 79(7):1147-1156.

5. Rosen ED, MacDougald OA: Adipocyte differentiation from the inside out. Nat Rev Mol Cell Biol 2006, 7(12):885-896.

6. Farmer SR: Transcriptional control of adipocyte formation. Cell Metab 2006, 4(4):263-273.

7. Barak Y, Nelson MC, Ong ES, Jones YZ, Ruiz-Lozano P, Chien KR, Koder A, Evans RM: PPAR gamma is required for placental, cardiac, and adipose tissue development. Mol Cell 1999, 4(4):585-595.

8. Rosen ED, Sarraf P, Troy AE, Bradwin G, Moore K, Milstone DS, Spiegelman $\mathrm{BM}$, Mortensen RM: PPAR gamma is required for the differentiation of adipose tissue in vivo and in vitro. Mol Cell 1999, 4(4):611-617.

9. Schupp M, Cristancho AG, Lefterova MI, Hanniman EA, Briggs ER, Steger DJ, Qatanani M, Curtin JC, Schug J, Ochsner SA, McKenna NJ, MA L: Re-expression of GATA2 cooperates with peroxisome proliferatoractivated receptor-gamma depletion to revert the adipocyte phenotype. J Biol Chem 2009, 284(14):9458-9464.

10. Imai T, Takakuwa R, Marchand S, Dentz E, Bornert JM, Messaddeq N, Wendling O, Mark M, Desvergne B, Wahli W, Chambon P, Metzger D: Peroxisome proliferator-activated receptor gamma is required in mature white and brown adipocytes for their survival in the mouse. Proc Natl Acad Sci U S A 2004, 101(13):4543-4547.

11. Monajemi $\mathrm{H}$, Zhang L, Li G, Jeninga $\mathrm{EH}$, $\mathrm{Cao} H$, Maas M, Brouwer CB, Kalkhoven E, Stroes E, Hegele RA, Leff T: Familial partial lipodystrophy phenotype resulting from a single-base mutation in deoxyribonucleic acid-binding domain of peroxisome proliferator-activated receptorgamma. J Clin Endocrinol Metab 2007, 92(5):1606-1612.

12. Agarwal AK, Garg A: A novel heterozygous mutation in peroxisome proliferator-activated receptor-gamma gene in a patient with familial partial lipodystrophy. J Clin Endocrinol Metab 2002, 87(1):408-411.

13. Hegele RA, Cao H, Frankowski C, Mathews ST, Leff T: PPARG F388L, a transactivation-deficient mutant, in familial partial lipodystrophy. Diabetes 2002, 51(12):3586-3590.

14. Lehmann JM, Moore LB, Smith-Oliver TA, Wilkison WO, Willson TM, Kliewer SA: An antidiabetic thiazolidinedione is a high affinity ligand for peroxisome proliferator-activated receptor gamma (PPAR gamma). J Biol Chem 1995, 270(22):12953-12956.

15. Rosen CJ: The rosiglitazone story - lessons from an FDA advisory committee meeting. N Engl J Med 2007, 357(9):844-846.

16. Zhu Y, Qi C, Korenberg JR, Chen XN, Noya D, Rao MS, Reddy JK: Structural organization of mouse peroxisome proliferator-activated receptor gamma (mPPAR gamma) gene: alternative promoter use and different splicing yield two mPPAR gamma isoforms. Proc Natl Acad Sci U S A 1995, 92(17):7921-7925.

17. Fajas $L$, Auboeuf $D$, Raspe E, Schoonjans K, Lefebvre AM, Saladin R, Najib J, Laville M, Fruchart JC, Deeb S, Vidal-Puig A, Flier J, Briggs MR, Staels B, Vidal $H$, Auwerx J: The organization, promoter analysis, and expression of the human PPARgamma gene. J Biol Chem 1997, 272(30):18779-18789.

18. Jitrapakdee S, Slawik M, Medina-Gomez G, Campbell M, Wallace JC, Sethi JK, O'Rahilly S, Vidal-Puig AJ: The peroxisome proliferator-activated receptor- 
gamma regulates murine pyruvate carboxylase gene expression in vivo and in vitro. J Biol Chem 2005, 280(29):27466-27476.

19. Cho YW, Hong S, Jin Q, Wang L, Lee JE, Gavrilova O, Ge K: Histone methylation regulator PTIP is required for PPARgamma and C/EBPalpha expression and adipogenesis. Cell Metab 2009, 10(1):27-39.

20. Kornberg RD, Lorch Y: Twenty-five years of the nucleosome, fundamental particle of the eukaryote chromosome. Cell 1999, 98(3):285-294.

21. Luger K, Mader AW, Richmond RK, Sargent DF, Richmond TJ: Crystal structure of the nucleosome core particle at $2.8 \mathrm{~A}$ resolution. Nature 1997, 389(6648):251-260.

22. Jenuwein T, Allis CD: Translating the histone code. Science 2001, 293(5532):1074-1080.

23. Knezetic JA, Luse DS: The presence of nucleosomes on a DNA template prevents initiation by RNA polymerase II in vitro. Cell 1986, 45(1):95-104.

24. Lee CK, Shibata Y, Rao B, Strahl BD, Lieb JD: Evidence for nucleosome depletion at active regulatory regions genome-wide. Nat Genet 2004, 36(8):900-905

25. Kingston RE, Narlikar GJ: ATP-dependent remodeling and acetylation as regulators of chromatin fluidity. Genes Dev 1999, 13(18):2339-2352

26. Cote J, Peterson CL, Workman JL: Perturbation of nucleosome core structure by the SWI/SNF complex persists after its detachment, enhancing subsequent transcription factor binding. Proc Natl Acad Sci U S A 1998, 95(9):4947-4952.

27. Hamiche A, Sandaltzopoulos R, Gdula DA, Wu C: ATP-dependent histone octamer sliding mediated by the chromatin remodeling complex NURF. Cell 1999, 97(7):833-842.

28. Strahl BD, Allis CD: The language of covalent histone modifications. Nature 2000, 403(6765):41-45.

29. Kouzarides T: Chromatin modifications and their function. Cell 2007, 128(4):693-705.

30. Jin Q, Yu L-R, Wang L, Zhang Z, Kasper LH, Lee J-E, Wang C, Brindle PK, Dent SYR, Ge K: Distinct roles of GCN5/PCAF-mediated H3K9ac and CBP/p300mediated $\mathrm{H} 3 \mathrm{~K} 18 / 27$ ac in nuclear receptor transactivation. EMBO J 2011 30(2):249-262.

31. Marmorstein R, Roth SY: Histone acetyltransferases: function, structure, and catalysis. Curr Opin Genet Dev 2001, 11(2):155-161.

32. Ayer DE: Histone deacetylases: transcriptional repression with SINers and NuRDs. Trends Cell Biol 1999, 9(5):193-198.

33. Li X, Corsa CA, Pan PW, Wu L, Ferguson D, Yu X, Min J, Dou Y: MOF and H4 K16 acetylation play important roles in DNA damage repair by modulating recruitment of DNA damage repair protein $\mathrm{Mdc1}$. Mol Cell Biol 2010, 30(22):5335-5347.

34. Kueh AJ, Dixon MP, Voss AK, Thomas T: HBO1 is required for $\mathrm{H} 3 \mathrm{~K} 14$ acetylation and normal transcriptional activity during embryonic development. Mol Cell Biol 2011, 31(4):845-860.

35. Barski A, Cuddapah S, Cui K, Roh T-Y, Schones DE, Wang Z, Wei G, Chepelev I, Zhao K: High-resolution profiling of histone methylations in the human genome. Cell 2007, 129(4):823-837.

36. Li B, Carey M, Workman JL: The role of chromatin during transcription. Cell 2007, 128(4):707-719.

37. Santos-Rosa H, Schneider R, Bannister AJ, Sherriff J, Bernstein BE, Emre NC Schreiber SL, Mellor J, Kouzarides T: Active genes are tri-methylated at K4 of histone H3. Nature 2002, 419(6905):407-411.

38. Calo E, Wysocka J: Modification of enhancer chromatin: what, how, and why? Mol Cell 2013, 49(5):825-837.

39. Ge K: Epigenetic regulation of adipogenesis by histone methylation. Biochim Biophys Acta 2012, 1819(7):727-732

40. Shi Y: Histone lysine demethylases: emerging roles in development, physiology and disease. Nat Rev Genet 2007, 8(11):829-833.

41. Lane MD, Tang Q-Q, Jiang M-S: Role of the CCAAT Enhancer Binding Proteins (C/EBPs) in adipocyte differentiation. Biochem Biophys Res Commun 1999, 266(3):677.

42. Landschulz WH, Johnson PF, MCKnight SL: The DNA binding domain of the rat liver nuclear protein C/EBP is bipartite. Science 1989, 243(4899):1681-1688.

43. Cao Z, Umek RM, McKnight SL: Regulated expression of three C/EBP isoforms during adipose conversion of 3T3-L1 cells. Genes Dev 1991, 5(9):1538-1552.

44. Wu Z, Xie Y, Bucher NL, Farmer SR: Conditional ectopic expression of C/EBP beta in NIH-3T3 cells induces PPAR gamma and stimulates adipogenesis. Genes Dev 1995, 9(19):2350-2363.
45. Wu Z, Bucher NL, Farmer SR: Induction of peroxisome proliferatoractivated receptor gamma during the conversion of $3 \mathrm{~T} 3$ fibroblasts into adipocytes is mediated by C/EBPbeta, C/EBPdelta, and glucocorticoids. Mol Cell Biol 1996, 16(8):4128-4136.

46. Tanaka T, Yoshida N, Kishimoto T, Akira S: Defective adipocyte differentiation in mice lacking the C/EBPbeta and/or C/EBPdelta gene. EMBO J 1997, 16(24):7432-7443.

47. Wang ND, Finegold MJ, Bradley A, Ou CN, Abdelsayed SV, Wilde MD, Taylor LR, Wilson DR, Darlington GJ: Impaired energy homeostasis in C/EBP alpha knockout mice. Science 1995, 269(5227):1108-1112.

48. Salma N, Xiao H, Imbalzano AN: Temporal recruitment of CCAAT/ enhancer-binding proteins to early and late adipogenic promoters in vivo. $J$ Mol Endocrinol 2006, 36(1):139-151.

49. Clarke SL, Robinson CE, Gimble JM: CAAT/enhancer binding proteins directly modulate transcription from the peroxisome proliferatoractivated receptor gamma 2 promoter. Biochem Biophys Res Commun 1997, 240(1):99-103.

50. Lee JE, Wang C, Xu S, Cho YW, Wang L, Feng X, Baldridge A, Sartorelli V, Zhuang L, Peng W, Ge K: H3K4 mono- and di-methyltransferase MLL4 is required for enhancer activation during cell differentiation. eLife 2013, 2:e01503.

51. Siersbaek R, Nielsen R, John S, Sung MH, Baek S, Loft A, Hager GL, Mandrup S: Extensive chromatin remodelling and establishment of transcription factor 'hotspots' during early adipogenesis. EMBO J 2011, 30(8):1459-1472.

52. Siersbaek R, Nielsen R, Mandrup S: Transcriptional networks and chromatin remodeling controlling adipogenesis. Trends Endocrinol Metab 2012, 23(2):56-64

53. Lin $H$, Grosschedl R: Failure of B-cell differentiation in mice lacking the transcription factor EBF. Nature 1995, 376(6537):263-267.

54. Kieslinger M, Folberth S, Dobreva G, Dorn T, Croci L, Erben R, Consalez GG, Grosschedl R: EBF2 regulates osteoblast-dependent differentiation of osteoclasts. Dev Cell 2005, 9(6):757-767.

55. Jimenez MA, Akerblad P, Sigvardsson M, Rosen ED: Critical role for Ebf1 and Ebf2 in the adipogenic transcriptional cascade. Mol Cell Biol 2007 27(2):743-757

56. Akerblad P, Lind U, Liberg D, Bamberg K, Sigvardsson M: Early B-cell factor $(\mathrm{O} / \mathrm{E}-1)$ is a promoter of adipogenesis and involved in control of genes important for terminal adipocyte differentiation. Mol Cell Biol 2002, 22(22):8015-8025

57. Rajakumari S, Wu J, Ishibashi J, Lim HW, Giang AH, Won KJ, Reed RR, Seale P: EBF2 determines and maintains brown adipocyte identity. Cell Metab 2013, 17(4):562-574.

58. Birsoy K, Chen Z, Friedman J: Transcriptional regulation of adipogenesis by KLF4. Cell Metab 2008, 7(4):339-347.

59. Oishi Y, Manabe I, Tobe K, Tsushima K, Shindo T, Fujiu K, Nishimura G, Maemura K, Yamauchi T, Kubota N, Suzuki R, Kitamura T, Akira S, Kadowaki T, Nagai R: Kruppel-like transcription factor KLF5 is a key regulator of adipocyte differentiation. Cell Metab 2005, 1(1):27-39.

60. Pei H, Yao Y, Yang Y, Liao K, Wu JR: Kruppel-like factor KLF9 regulates PPARgamma transactivation at the middle stage of adipogenesis. Cell Death Differ 2011, 18(2):315-327.

61. Mori T, Sakaue H, lguchi H, Gomi H, Okada Y, Takashima Y, Nakamura K, Nakamura T, Yamauchi T, Kubota N, Kadowaki T, Matsuki Y, Ogawa W, Hiramatsu R, Kasuga M: Role of Kruppel-like factor 15 (KLF15) in transcriptional regulation of adipogenesis. J Biol Chem 2005, 280(13):12867-12875.

62. Banerjee SS, Feinberg MW, Watanabe M, Gray S, Haspel RL, Denkinger DJ, Kawahara R, Hauner H, Jain MK: The Kruppel-like factor KLF2 inhibits peroxisome proliferator-activated receptor-gamma expression and adipogenesis. J Biol Chem 2003, 278(4):2581-2584.

63. Yokoyama C, Wang X, Briggs MR, Admon A, Wu J, Hua X, Goldstein JL, Brown MS: SREBP-1, a basic-helix-loop-helix-leucine zipper protein that controls transcription of the low density lipoprotein receptor gene. Cell 1993, 75(1):187-197.

64. Tontonoz P, Kim JB, Graves RA, Spiegelman BM: ADD1: a novel helix-loophelix transcription factor associated with adipocyte determination and differentiation. Mol Cell Biol 1993, 13(8):4753-4759.

65. Kim JB, Spiegelman BM: ADD1/SREBP1 promotes adipocyte differentiation and gene expression linked to fatty acid metabolism. Genes Dev 1996, 10(9):1096-1107.

66. Fajas L, Schoonjans K, Gelman L, Kim JB, Najib J, Martin G, Fruchart JC, Briggs M, Spiegelman BM, Auwerx J: Regulation of peroxisome 
proliferator-activated receptor gamma expression by adipocyte differentiation and determination factor $1 /$ sterol regulatory element binding protein 1: implications for adipocyte differentiation and metabolism. Mol Cell Biol 1999, 19(8):5495-5503.

67. Gupta RK, Arany Z, Seale P, Mepani RJ, Ye L, Conroe HM, Roby YA, Kulaga H, Reed RR, Spiegelman BM: Transcriptional control of preadipocyte determination by Zfp423. Nature 2010, 464(7288):619-623.

68. Waki H, Nakamura M, Yamauchi T, Wakabayashi K, Yu J, Hirose-Yotsuya L, Take K, Sun W, Iwabu M, Okada-Iwabu M, Fujita T, Aoyama T, Tsutsumi S, Ueki K, Kodama T, Sakai J, Aburatani H, Kadowaki T: Global mapping of cell typespecific open chromatin by FAIRE-seq reveals the regulatory role of the NFI family in adipocyte differentiation. PLoS Genet 2011, 7(10):e1002311.

69. Wu Z, Rosen ED, Brun R, Hauser S, Adelmant G, Troy AE, McKeon C, Darlington GJ, Spiegelman BM: Cross-regulation of C/EBP alpha and PPAR gamma controls the transcriptional pathway of adipogenesis and insulin sensitivity. Mol Cell 1999, 3(2):151-158.

70. Lefterova MI, Zhang Y, Steger DJ, Schupp M, Schug J, Cristancho A, Feng D, Zhuo D, Stoeckert CJ Jr, Liu XS, Lazar MA: PPARgamma and C/EBP factors orchestrate adipocyte biology via adjacent binding on a genome-wide scale. Genes Dev 2008, 22(21):2941-2952.

71. Nielsen R, Pedersen TA, Hagenbeek D, Moulos P, Siersbaek R, Megens E, Denissov S, Borgesen M, Francoijs K-J, Mandrup S, Stunnenberg HG: Genome-wide profiling of PPAR\{gamma\}:RXR and RNA polymerase II occupancy reveals temporal activation of distinct metabolic pathways and changes in RXR dimer composition during adipogenesis. Genes Dev 2008, 22(21):2953-2967.

72. Tong $\mathrm{Q}$, Dalgin $\mathrm{G}, \mathrm{Xu} \mathrm{H}$, Ting $\mathrm{CN}$, Leiden $\mathrm{JM}$, Hotamisligil GS: Function of GATA transcription factors in preadipocyte-adipocyte transition. Science 2000, 290(5489):134-138.

73. Tong Q, Tsai J, Tan G, Dalgin G, Hotamisligil GS: Interaction between GATA and the C/EBP family of transcription factors is critical in GATA-mediated suppression of adipocyte differentiation. Mol Cell Biol 2005, 25(2):706-715.

74. Xiao H, Leblanc SE, Wu Q, Konda S, Salma N, Marfella CG, Ohkawa Y, Imbalzano AN: Chromatin accessibility and transcription factor binding at the PPARgamma2 promoter during adipogenesis is protein kinase A-dependent. J Cell Physiol 2011, 226(1):86-93.

75. Salma N, Xiao H, Mueller E, Imbalzano AN: Temporal recruitment of transcription factors and SWI/SNF chromatin-remodeling enzymes during adipogenic induction of the peroxisome proliferator-activated receptor gamma nuclear hormone receptor. Mol Cell Biol 2004, 24(11):4651-4663.

76. Mikkelsen TS, Xu Z, Zhang X, Wang L, Gimble JM, Lander ES, Rosen ED: Comparative epigenomic analysis of murine and human adipogenesis. Cell 2010, 143(1):156-169.

77. Steger DJ, Grant GR, Schupp M, Tomaru T, Lefterova MI, Schug J, Manduchi E, Stoeckert CJ Jr, Lazar MA: Propagation of adipogenic signals through an epigenomic transition state. Genes Dev 2010, 24(10):1035-1044.

78. Takahashi N, Kawada T, Yamamoto T, Goto T, Taimatsu A, Aoki N, Kawasaki H, Taira K, Yokoyama KK, Kamei Y, Fushiki T: Overexpression and ribozymemediated targeting of transcriptional coactivators CREB-binding protein and $\mathrm{p} 300$ revealed their indispensable roles in adipocyte differentiation through the regulation of peroxisome proliferator-activated receptor gamma. J Biol Chem 2002, 277(19):16906-16912.

79. Creyghton MP, Cheng AW, Welstead GG, Kooistra T, Carey BW, Steine EJ, Hanna J, Lodato MA, Frampton GM, Sharp PA, Boyer LA, Young RA, Jaenisch R: Histone H3K27ac separates active from poised enhancers and predicts developmental state. Proc Natl Acad Sci U S A 2010, 107(50):21931-21936.

80. Taipale M, Rea S, Richter K, Vilar A, Lichter P, Imhof A, Akhtar A: hMOF histone acetyltransferase is required for histone $\mathrm{H} 4$ lysine 16 acetylation in mammalian cells. Mol Cell Biol 2005, 25(15):6798-6810.

81. Wang L, Xu S, Lee J-E, Baldridge A, Grullon S, Peng W, Ge K: Histone H3K9 methyltransferase G9a represses PPAR [gamma] expression and adipogenesis. EMBO J 2013, 32(1):45-59.

82. Musri MM, Carmona MC, Hanzu FA, Kaliman P, Gomis R, Parrizas M: Histone demethylase LSD1 regulates adipogenesis. J Biol Chem 2010, 285(39):30034-30041.

83. Wang L, Jin Q, Lee JE, Su IH, Ge K: Histone H3K27 methyltransferase Ezh2 represses Wnt genes to facilitate adipogenesis. Proc Natl Acad Sci U S A 2010, 107(16):7317-7322

84. Cho Y-W, Hong T, Hong S, Guo H, Yu H, Kim D, Guszczynski T, Dressler GR, Copeland TD, Kalkum M, Ge K: PTIP associates with MLL3- and MLL4- containing histone $\mathrm{H} 3$ lysine 4 methyltransferase complex. J Biol Chem 2007, 282(28):20395-20406

85. Ruthenburg AJ, Allis CD, Wysocka J: Methylation of lysine 4 on histone $\mathrm{H3}$ : intricacy of writing and reading a single epigenetic mark. Mol Cell 2007, 25(1):15-30.

86. Vermeulen $\mathrm{M}$, Timmers $\mathrm{HT}$ : Grasping trimethylation of histone $\mathrm{H} 3$ at lysine 4. Epigenomics 2010, 2(3):395-406.

87. Cho YW, Hong S, Ge K: Affinity purification of MLL3/MLL4 histone H3K4 methyltransferase complex. Methods Mol Biol 2012, 809:465-472.

88. Hong S, Cho Y-W, Yu L-R, Yu H, Veenstra TD, Ge K: Identification of JmjC domain-containing UTX and JMJD3 as histone H3 lysine 27 demethylases. Proc Natl Acad Sci U S A 2007, 104(47):18439-18444.

89. Lee MG, Villa R, Trojer P, Norman J, Yan KP, Reinberg D, Di Croce L, Shiekhattar R: Demethylation of H3K27 regulates polycomb recruitment and H2A ubiquitination. Science 2007, 318(5849):447-450.

90. Patel SR, Kim D, Levitan I, Dressler GR: The BRCT-domain containing protein PTIP links PAX2 to a histone $\mathrm{H} 3$, lysine 4 methyltransferase complex. Dev Cell 2007, 13(4):580.

91. Lee J, Saha PK, Yang Q-H, Lee S, Park JY, Suh Y, Lee S-K, Chan L, Roeder RG, Lee JW: Targeted inactivation of MLL3 histone H3-Lys-4 methyltransferase activity in the mouse reveals vital roles for MLL3 in adipogenesis. Proc Nat Acad Sci 2008, 105(49):19229-19234.

92. Qi C, Surapureddi S, Zhu Y-J, Yu S, Kashireddy P, Rao MS, Reddy JK: Transcriptional coactivator PRIP, the peroxisome proliferator-activated receptor \{gamma\} (PPAR\{gamma\})-interacting protein, is required for PPAR\{gamma\}-mediated adipogenesis. J Biol Chem 2003, 278(28):25281-25284.

93. Rice JC, Briggs SD, Ueberheide B, Barber CM, Shabanowitz J, Hunt DF, Shinkai Y, Allis CD: Histone methyltransferases direct different degrees of methylation to define distinct chromatin domains. Mol Cell 2003, 12(6):1591-1598.

94. Tachibana M, Sugimoto K, Nozaki M, Ueda J, Ohta T, Ohki M, Fukuda M, Takeda N, Niida H, Kato H, Shinkai Y: G9a histone methyltransferase plays a dominant role in euchromatic histone H3 lysine 9 methylation and is essential for early embryogenesis. Genes Dev 2002, 16(14):1779-1791.

95. Pasini D, Bracken AP, Hansen JB, Capillo M, Helin K: The polycomb group protein Suz12 is required for embryonic stem cell differentiation. Mol Cell Biol 2007, 27(10):3769-3779.

96. Cristancho AG, Lazar MA: Forming functional fat: a growing understanding of adipocyte differentiation. Nat Rev Mol Cell Biol 2011, 12(11):722-734.

97. Zentner GE, Scacheri PC: The chromatin fingerprint of gene enhancer elements. J Biol Chem 2012, 287(37):30888-30896.

98. Cong L, Ran FA, Cox D, Lin S, Barretto R, Habib N, Hsu PD, Wu X, Jiang W, Marraffini LA, Zhang F: Multiplex genome engineering using CRISPR/Cas systems. Science 2013, 339(6121):819-823.

99. Tsai MC, Manor O, Wan Y, Mosammaparast N, Wang JK, Lan F, Shi Y, Segal $\mathrm{E}$, Chang HY: Long noncoding RNA as modular scaffold of histone modification complexes. Science 2010, 329(5992):689-693.

100. Lee JT: Lessons from X-chromosome inactivation: long ncRNA as guides and tethers to the epigenome. Genes Dev 2009, 23(16):1831-1842.

101. Sun L, Goff LA, Trapnell C, Alexander R, Lo KA, Hacisuleyman E, Sauvageau M, Tazon-Vega B, Kelley DR, Hendrickson DG, Yuan B, Kellis M, Lodish HF, Rinn JL: Long noncoding RNAs regulate adipogenesis. Proc Natl Acad SCi U S A 2013, 110(9):3387-3392.

102. Tolhuis B, Palstra RJ, Splinter E, Grosveld F, de Laat W: Looping and interaction between hypersensitive sites in the active beta-globin locus. Mol Cell 2002, 10(6):1453-1465.

103. Dekker J, Rippe K, Dekker M, Kleckner N: Capturing chromosome conformation. Science 2002, 295(5558):1306-1311.

104. Fraser P, Bickmore W: Nuclear organization of the genome and the potential for gene regulation. Nature 2007, 447(7143):413-417.

doi:10.1186/2045-3701-4-29

Cite this article as: Lee and Ge: Transcriptional and epigenetic regulation of PPARY expression during adipogenesis. Cell \& Bioscience 2014 4:29. 